\title{
Linking Liberatory Pedagogy to Engineering and Sustainable Development
}

\author{
Jayasubamani Arvi S. Moganakrishnann ${ }^{1, *}$, Satesh Narayana Namasivayam² , and \\ NurHazwani Ismail $^{3}$ \\ 1,2,3 Taylor's School of Engineering, Taylor's University Lakeside Campus, No. 1, Jalan Taylor's, \\ 47500 Subang Jaya, Selangor Darul Ehsan, Malaysia
}

\begin{abstract}
This paper is written to link liberatory pedagogy with engineering education and sustainable development Its application to specifically, design education for community is explored through deconstructing of engineering student narratives to place understanding of power and privilege in a specific learning setting. The use of liberatory pedagogy for design education and SD is attempted where there is need of changes in understanding of learning outcomes for SD aimed at producing of sustainable physical products to address SD problems in communitybased projects. We argue against the simple-minded approach of producing physical products and undermine the intersections of other knowledge forms within the community context. Without pedagogic intervention, we undermine other knowledge forms and cultures in its importance amidst technical knowledge seen as which is valid for SD. Extending liberatory pedagogy to constructivists' perspective we discuss the importance of intervention in the broader image of the engineer as the technical expert who share knowledge in partnership for SD.
\end{abstract}

\section{Introduction}

Engineering education and sustainable development (SD) are linked by many pedagogies which has brought possibilities for development of young engineers to acknowledge the agenda as imperative for engineering and society in the future[1]-[3]. These pedagogies have been highlighted in its benefit in bringing understanding of concepts, practice and values in relation to SD which stems from the educational efforts within Educational research undertaken particularly, from Environmental Education and Education for Sustainable Development (ESD)[4], [5]. University curricula for engineering has contributed to the development as well, framed under the Engineering Education for Sustainable Development initiative following the Barcelona Declaration and the Decade of Education for Sustainable Development (2005-2014)[6] for implementation of educational programs in link with SD .In terms of engineering education, incorporation of sustainability within the curriculum has led to exploration of relevant module to discuss sustainability as

* Corresponding author: jayasubamani@gmail.com 
well as unsustainability as that which needs to be addressed particularly for professional development[2], [6]-[8]. Within engineering education, design education has received specific attention in its potential to be a constructive activity for the application of highly cognitive skills for learning of producing of solutions in the form of physical products[9][11]. A trend of changes to design education is noted within the literature which emphasizes on embracing of multidisciplinary towards transdisciplinary approaches which involves a more comprehensive approach towards understanding of problems solving particularly the problems raised as affecting human well-being and environment [6], [10], [12].

On the other hand, SD becomes understood as development practices which involves problem solving and decision making which are multidimensional, diverse and complex[2], [13]-[15]. This is due to involvement of people, culture and environment, pedagogies which are in support of transformative approaches are relevant with critical implementation of collaborative, intersubjective approaches seeking partnership of others involved[16]-[18]. Transformative approaches are approaches which deals with changing of perspectives, particularly relevant with regards to understanding how people, culture and environment interact in resulting sustainability and unsustainability and our changing roles in addressing them. One area of such transformation is working across discipline, being transgressive towards addressing of complexity in problem [19], [20]. Such transformation is detailed by many literatures seeking transdisciplinary imagination to build our capacity towards addressing complex problems in a . Transdisciplinary initiatives would require us to open our design space in a synergistic approach in which we could understand how we could understand contributing as part to the fresh new 'whole'. With relevance to engineering design education, bringing design into the societal domain with the current mainstream construction for such transdisciplinary endeavors may be problematic in terms of the ideals and mechanistic pathways of simplified education we prescribe to.

Reflection of such critical experiences within engineering education brings test to assumption that educational process which are constructed can be neutral, performed in positivic tradition of achieving outcomes as conceptualized without understanding society. A pedagogy which can support critical study of educational implementations for the students is critical pedagogy, aimed at deconstructing power and privileges within the narratives which inform the learning process and become dominating pathways which eliminates others and their ways of knowledge .

This paper aims to construct the liberatory pedagogy as concept, its origin as well as its worth to problematize current prevailing ideology for design education for EESD. It hopes to address the needed changes to bring possibilities for engineering students to take active roles in society with understanding of power and privileges which leads to oppression and unsustainability.

\section{What is liberatory pedagogy?}

Critical pedagogy was introduced by Paulo Friere through his seminal work, Pedagogy of the Oppressed published in 1968[16], [17]. It is a teaching approach informed by his work as well as other radical philosophies focusing on helping of students deal with the problematic world requiring social justice through questions. These questions are constructed to challenge dominant views which also undermine other understanding, practices and privileges certain views and knowledge. Given these premises, it becomes an 
approach to help students achieve critical consciousness which relates to critical thinking in reflexivity of their social and cultural positions. In terms of engineering, it is particularly relevant amidst their professional roles within the societal context such as designing for community.

In this tradition, the focus is on the educator and how efforts could be channeled towards directing the learners to question. The learners question the ideologies they prescribe to which dominate over other ideologies in addressing a whole. It refers to not considering whose interest are they representing for, in which they as diverse participants are participating in despite a homogenous intervention to gather them in a learning setting. Some of their views traditionally omitted or dismissed as they are taken for granted, even within their own institutional setting. Instead of imposing such views and expect conforming attitudes from the oppressed, the narratives spoken about each other or when they 'other' them, are deconstructed in terms of what they mean towards each other despite their participation for the whole. The deconstruction is led in a way that a legitimate, liberatory collective response through dialogue could be gathered as a fresh new perspective on the way they perceive each other as valued contributors to the whole.

Within the classroom setting, students learning begins to critically study the process in which they can begin to view that a practice in society deeply problematic. For example, in the way aboriginal groups are perceived as incompetent, unruly and uncivilized or women as incapable of technicalities or provide significant idea in equal to men. Upon presenting these views, they attempt to change the perceived oppression through constructive methods which allows them to act in direction of a collective response, in respect of those who have been oppressed by the system.

Within the classroom setting, students' learning begins to critically study the process in which they can begin to view that a practice in society deeply problematic. For example, narratives presented in the way we perceive aboriginal groups as incompetent, unruly and uncivilized or women as incapable of technicalities or provide significant ideas in equal to men. Upon presenting these views, they attempt to change the perceived oppression through constructive methods (i.e dialogue) which allows them to act in direction of a collective response, in respect of those who have been oppressed by the system.

Within sustainable development, such dialogue-oriented platforms have been identified as pertinent in bringing a more democratic and inclusive approach to bringing of learning among those involved for development of partnership and collaboration[21]. Dialogues are important communicative platforms in which we could address our differences constructively and reflexively in effort to build a collective through learning[17]. Critical pedagogy aims at providing such dialogueoriented platforms within the curriculum, which humanizes the unrepresented and brings dignity to their views to be included within context diversified. As a critical approach, it allows educators to bring changes in building collective response in addressing issues found problematic in society particularly sustainability which is informed both socially and culturally in an overlap with .

Critical pedagogy has been explored mainly through the post formal educational thinking which champions education which emancipates the thinking of the unrepresented[3], [22]. This includes gender, religion, Eastern culture as well 
different abilities in challenged individuals which remain unaddressed in an education system which is mainly colonial, Western, abled and male. Although it is also argued that the approach has been championed towards transformation in context which are predominantly Western, progressive in nature and thus, may in fact destruct any traditionalist view which may be conserving the communities which it intends to represent. However, within the context of engineering education, its use may find purpose in challenging its conservative approach which limits participation and opens the cultural context to not null others and state the engineer as fixed in his image on being technoeconomic but build the reflexive engineer in support of sustainable community development.

Within engineering education, it remains rare although recent call from the engineering education research has highlighted the need to look in specific towards critical experiences in . Given the attention, certain perspectives through critical pedagogy has been explored. Using feminism in an objectivized, Western, male oriented subject such as thermodynamics is an eye opener towards use of the pedagogy in representing meaningful engineering education for women as well as other participants like international students from the East[23]-[25]. Riley used feminism in way to identify use of thermodynamics principles in applications across a diverse selection which includes inventions from untypical sources such as invented for cooking or invented in the East[24]. The use of introducing sustainable technologies not only from the Western male society but also the Eastern as well as from women inventors such as the bain-marie (double boiler) which has failed to be mentioned in most thermodynamic courses[23]. Riley also denotes the critical situation of us as educators linking critical experiences in engineering education limitedly framed to represent highly cognitive efforts and not which affects the development of the self, in our reflexive position in society[23]. However, other areas of engineering education particularly design context is yet to be discussed although the context in link with SD warrants the need for participatory context.

Understanding on the reflexivity and engineer has been discussed in terms of involvement in community development which seeks greater representation of the community within any intervention for their development as discussion of power and privileges of the engineer in their position in society. Robbins [26] discuss the perception engineers working in the context of community of their own position which are controlling in nature and inappreciative of the local knowledge which affects their opinion of the image of the engineer. Engineers discussed seem to find it difficult to accept representation of others as content of knowledge providers, potentially fits them under the label of providers of valuable information and dismiss their engagement as imperative as to technical knowledge. With regards to engineering education, the lack of community representation within the context of pedagogical approach for learning of SD become the discussion point of [27], [28]. The articles highlight the need for critical approaches within design in link with sustainable development for engineering education. In terms of critical pedagogy, it is a useful pathway in the interest of developing communicative platform from the classroom to problematize society with facilitation of engineering educators, who in their position understand critically of their changing roles both socially and culturally in facilitating development of active roles of engineers for community.

The following section will depict how critical pedagogy could be explored within the context of design education for engineers and sustainable development through 
educators perspective. It details examples of participatory context and descriptions of participating diverse partners involving engineers as well as narratives identified within the teaching setting of the authors which require further discussion on the link of critical pedagogy with design and sustainable development for engineering education.

\section{Liberatory Pedagogy for Design}

Design education is an important element of the education of engineers which has link to development of expertise as well as identity as designers. Through design education, they learn the trajectory of responding to client requirement and explore the meaning of clientdesigner relationship through team work of many students in a team[29]. However, with regards to SD and education which works on building of capacity to address complex problems, incorporation of more comprehensive approaches towards inquiry of problems are used[6]. This includes multidisciplinary, interdisciplinary and transdisciplinary approaches which are implemented towards transforming the disciplinary mindset, working away from silos towards a transgressive mindset of crossing boundaries in view of the common problem which affects the interest of various parties[6], [30]-[32] .

However, mainstream design education for sustainable development in its mechanistic approach addressing objectivity in design may promote a neutral perspective to a product-oriented design learning process even for projects intended for a social or environmental need of communities. This process in turn creates unhealthy power relationship $\square \square$ between student and potential community of address as well as cognitive dissonance [33] with regards to the outcome which are reduced to a product which is not aligned to complex intersubjective experience [16], [34] of learning about people, space and technology through design and the issues of unsustainability.

Engineering design is a process of proceeding from problem defining based on the problems identified or explained by the client towards problem solving in the form of producing technical solution. As education, it does not allow us to understand intersubjectivity of the experience which involves people, space and technology. The values considered within the objectives of the process is depicted as static references to a social or environmental problem which may seems to correspond to a social need or environmental need. These values are not considered in a way which allows us to understand our views as intervening designers with the intention that our act of designing a physical product may solve a social or environmental problem in the living. As students who enters the intersubjective realm of complex relationships to a social and environmental problem, it does not allow us to see ourselves as emerging learning selves. The outcome which become simplified, reduced to a product that either satisfies the requirements of client or create a niche technology suggesting a technical perspective to a much more complex, multidimensional problem.

Student experience within involves projection of language which shows no reflexivity of privilege and power within the conversation which will obstruct the potential for these projects to reflect a partnership with community that they are addressing.

Within a project for the aboriginal community that was intended for providing access to clean water, discussion with educator reveals his views with dialogue entry 
from the educator. Students within this project have been able to conceptualize a rain water harvesting project proposal to provide access of water. However, when discussing questions to be asked to villagers on the details on the living of the aboriginal and how the project would intervene with their lifestyle, this conversation was noted

Educator : With regards to the project, we are going to visit the kampung (village) for you to talk to the villagers. Before we proceed, I would like to know what do you know about our Orang Asli (aboriginal)?

$\begin{array}{lll}\begin{array}{l}\text { Student } \\ \text { Educator }\end{array} & : & \text { They are uneducated, and live in uncivilized manner. } \\ \text { Student } & : & \begin{array}{l}\text { Why do you think so? } \\ \text { (Showing a disapproving body language)..They don't have much } \\ \text { facilities around them. Therefore, they are fine with living in the } \\ \text { poor way }\end{array} \\ \text { Educator } & : & \begin{array}{l}\text { What about the rest, what do you think? } \\ \text { Student }\end{array} \\ \text { Educator } & : & \begin{array}{l}\text { (Silent a while)... They don't have much knowledge } \\ \text { Do you need more knowledge to live here or to live within the } \\ \text { forest? }\end{array} \\ \text { Student } & : & \begin{array}{l}\text { Silent....wondering...showing facial expressions reflecting the } \\ \text { irrelevance of the question }\end{array}\end{array}$

The depiction of conversation above is an insight to into the conversations between an educator involved in constructing education linking designing to sustainable development and engineering design students working on a project for the aboriginals. The conversation depicts the thinking of engineering student lack of awareness coming from a privileged background to understand the difficult sociohistorical conditions of the aboriginal which results in a discriminatory stance against the aboriginals they are intending to design for. The educator questioning is intended to reflect on the educational practice which incorporates the aboriginals as clients requiring a solution for clean water provision. As the current design pedagogy only requires input of problem definition without understanding sociohistorical conditions and its impact towards community deriving solutions put the engineering students in an unhealthy relationship towards building of partnership between the community they work for and themselves.

As educators, our understanding of aboriginal condition in our countries helps to lead discussion in a communicative way to help students to deconstruct their views to respond collectively as reflexive engineers who address the situation with empathy. The aboriginal living conditions around the world have become a focus [35], [36]particularly within sustainable development agenda where these communities are fighting back for their privilege towards an education that does not marginalize and access to their deprived land[37]. Within Malaysia, the aboriginal community condition has become a political focus in the recent within the National Transformational Plan[37]. The aboriginals living conditions have become focus particularly with regards to their education as dignified native citizens of Malaysia who have been marginalized by the current mainstream education . The lack of access to resources like water resulting in a socio environmental problem is also reflected within their community. The aboriginals' identification with these resources through their lifestyle such as catching fish and diving reflects a closer relationship but have been limited due to development of the mountains and hills 
where these resources are found. Despite having profound knowledge of the forest, their conditions which in turn has led them to reservation lands has made it difficult to access of water and fulfilled, dignified living.

Our position as designers are to be considered in terms of understanding of our power relationships when working with these communities. In partnership, a designer is sharing his or her knowledge and in turn is informed of other kind of knowledge within a process of collective inquiry . Our lending of expertise is among others who also contribute content through personal experiences, mutual place-based experience as well as holistic knowledge such as art and indigenous technology. We also recognize our knowledge among others in a synoptic process[19] which in turns builds the bigger picture, the picture of the whole in relevance to a collective response to a condition of unsustainability.

The use of liberatory pedagogy within this context would challenge the mainstream design education which simplifies the design process as that which involves technicalities as outcome. Liberatory pedagogues help students to pose questions in view of the domination of practices that does not permit learning in a critical and reflexive way. The use of liberatory pedagogy in design would involve reflexive process of the intersubjective experience in understanding knowledge of the people in informing the unsustainability in the living. For example, understanding of the wells and streams used by the aboriginals to gain water and their introspective experience of how it might be changing and affecting their lives. With regards to access to clean water, with the knowledge shared, we might be able to decide if the critical condition is to be solved with what kind of social environmental intervention. For example, do we have a problem of water availability or water treatment which provide a more socially robust knowledge from our understanding informed of socio-environmental knowledge as well as technical knowledge.

Liberatory pedagogy could also help to build our understanding on the emerging our new, learning selves from the intersubjective process of being affected by the situation resulting in an empathic stance instead of technicality[16]. Other than our technical selves, our social and cultural roles which emerges because of the interaction between people, technology and space results in a more compassionate engineer who values learning as part of the development process. Vare and Scott [38] emphasizes such outcomes in their reference within ESD as that which helps towards building of our capacity to deal with unsustainability, in reference towards learning as the main component of sustainable development. McKenzie relates to the intersubjectivity as a critical pathway towards participation for social action, a bottom up approach rather than the top down technological implementation approach. With relevance to these perspectives is Ekins[39] view of sustainable development efforts within developing countries which would involve technology transfer as its main phase of change which mainly involves changes in the field and not in the top level of planning and management.

Potential criticism of this perspective could stem from the deviation of building expertise, resulting in dilution of competency as well as subjectivity which introduces uncertainty within the philosophical tradition of objectivity and functionality. Molinga [40] denotes with regards water professionals fear of dilution of expertise in the progressive change being highlighted for engineers to become more transdiscipliuary, crossing boundaries in order to solve problems in taking 
various other roles. However, Brown [19], [20] asserts through her work on the development of the collective mind, the need to understand the self among the collective and how individuals contribute. Thus, with these arguments, liberative pedagogy is seen relevant in broadening the image of the engineer designer as one who is not limited to technicalities but is in the present as emerging in their learning as part of the collective response towards sustainability in society.

\section{Conclusion}

Thus, with linking liberatory pedagogy to design and sustainable development has been a constructionist's approach in the critical way for engineering education. This paper was written to be an eye opener of educational approaches within the critical pathways focusing on student experience of learning. As education have become a foremost proponent targeted with regards to sustainable development and building of our future, the engineer as the technical expert is limiting of an image in a rather complex platform requiring the play of their role.

Within this paper, liberatory pedagogy has been discussed in its use and its particular relevance to the engineering field based on efforts by educational pedagogues exploring opportunities to include them within engineering education. In light of this, the potential use of liberatory pedagogy was discussed within design education with arguments provided for challenging of the mainstream design education. Student narrative was used to discuss the context of delivering these approaches and its useful relevance in building the capacity of the engineer more than technical expert but in reflexive of their emerging social and cultural role when learning with others.

Potential criticism of taking such perspectives for design education was also discussed with iteration of the pedagogy as that which emancipates and not that limits the identity of the engineer.

\section{References}

1. Y. Sipos, B. Battisti, and K. Grimm, “Achieving transformative sustainability learning: engaging head, hands and heart," Int. J. Sustain. High. Educ., vol. 9, no. 1, pp. 68-86, (Jan. 2008).

2. D. Ferrer-Balas, J. Bruno, M. De Mingo, and R. Sans, “Advances in education transformation towards sustainable development at the Technical University of Catalonia, Barcelona,” Int. J. Sustain. High. Educ., vol. 5, no. 3, pp. 251-266, (Sep. 2004).

3. I. Thomas, "Critical Thinking, Transformative Learning, Sustainable Education, and Problem-Based Learning in Universities," J. Transform. Educ., vol. 7, no. 3, pp. 245264, (Jul. 2009).

4. M. Pavlova, "Towards using transformative education as a benchmark for clarifying differences and similarities between Environmental Education and Education for Sustainable Development," Environ. Educ. Res., vol. 19, no. 5, pp. 656-672, (Nov. 2012). 
5. L. C. Palma et al., "Transformative learning to promote sustainability: inserting the third level of learning in management programs," Brazilian J. Sci. Technol., vol. 3, no. 1, p. 9, (Dec. 2016).

6. K. Kastenhofer, A. Lansu, R. van Dam-Mieras, and M. Sotoudeh, "The Contribution of University Curricula to Engineer ing Education for Sustainable Development," GAIAEcological Perspect. Sci. Soc., vol. 19(1), pp. 44-51, (2010).

7. K. W. Chau, "Incorporation of Sustainability Concepts into a Civil Engineering Curriculum," J. Prof. Issues Eng. Educ. Pract., vol. 133, no. 3, pp. 188-191, (2007).

8. B. Gagnon and R. S. Leduc, "Sustainable Development in Engineering: A Review of Principles and Definition of a Conceptual Framework.," Environ. Eng. Sci., vol. 26, no. 10, pp. 1459-1472, (2009).

9. A. I. Schäfer and B. S. Richards, "From concept to commercialisation: student learning in a sustainable engineering innovation project," Eur. J. Eng. Educ., vol. 32, no. 2, pp. 143-165, (2007).

10. D. Tate and T. E. Maxwell, "Transdisciplinary Approaches for Teaching and Assessing Sustainable Design.," Int. J. Eng. Educ., vol. 26, no. 2, pp. 418-429, (2010).

11. J. H. Spangenberg, A. Fuad-Luke, and K. Blincoe, "Design for Sustainability (DfS): The interface of sustainable production and consumption," J. Clean. Prod., vol. 18, no. 15, pp. 1483-1491, (2010).

12. D. S. Strong and O. C. K1, "Towards Effective Multidisciplinary Engineering Education : The Multidisciplinary Design Stream at Queen' s University Professor and NSERC Chair in Design Engineering," Proceedings of the Canadian Engineering Education Association. (2002).

13. P. Vare and W. Scott, "Learning for a Change: Exploring the Relationship Between Education and Sustainable Development," J. Educ. Sustain. Dev., vol. 1, no. 2, pp. 191198, Sep. (2007).

14. S. R. Sterling, Sustainable education: Revisioning learning and change. United Kingdom: Green Books for the Schumacher Society, (2001).

15. C. Hopkins and R. McKeown, "Education for Sustainable Development: past experience., present action and future prospects," Educ. Philos. Theory, vol. 33, no. 2, pp. 231-244, (2001).

16. M. McKenzie, "The places of pedagogy: or, what we can do with culture through intersubjective experiences," Environ. Educ. Res., (2008).

17. E. Ellsworth, “Why doesn't this feel empowering? Working through the repressive 
myths of critical pedagogy," Harv. Educ. Rev., (1989).

18. E. Ellsworth, Places of learning: Media, architecture, pedagogy. Routledge, (2005).

19. V. A. Brown, "Collective inquiry and its wicked problems," Tackling wicked Probl. through Transdiscipl. Imagin., pp. 61-83, (2010).

20. V. A. Brown, "Utopian thinking and the collective mind: Beyond transdisciplinarity," Futures, vol. 65, pp. 209-216, (2015).

21. T. Meppem and R. Gill, "Planning for sustainability as a learning concept," Ecol. Econ., vol. 26, no. 2, pp. 121-137, (Aug. 1998).

22. J. L. Kincheloe, Critical constructivism primer, vol. 2. Peter Lang, (2005).

23. D. Riley, "Employing liberative pedagogies in engineering education," J. Women Minor. Sci. Eng., vol. 9, no. 2, (2003).

24. D. Riley, A. L. Pawley, J. Tucker, and G. D. Catalano, "Feminisms in engineering education: Transformative possibilities," NWSA J., vol. 21, no. 2, pp. 21-40, (2009).

25. L. Claris and D. Riley, "Situation critical: critical theory and critical thinking in engineering education," Eng. Stud., vol. 4, no. 2, pp. 101-120, (2012).

26. P. T. Robbins, “The reflexive engineer: perceptions of integrated development," J. Int. Dev., vol. 19, no. 1, pp. 99-110, (2007).

27. J. Schneider and J. A. . L. Leydens, "Where is 'Community'?: Engineering education and sustainable community development.," Eur. J. Eng. Educ., vol. 33, no. 3, pp. 307319, (2008).

28. J. Lucena and J. Schneider, "Engineers, development, and engineering education: From national to sustainable community development.," Eur. J. Eng. Educ., vol. 33, no. 3, pp. 247-257, (2008).

29. C. L. Dym, A. M. Agogino, O. Eris, D. D. Frey, and L. J. Leifer, "Engineering design thinking, teaching, and learning," J. Eng. Educ., vol. 94, no. 1, pp. 103-120, (2005).

30. A. M. Lopes, D. Fam, and J. Williams, "Designing sustainable sanitation: Involving design in innovative, transdisciplinary research," Des. Stud., vol. 33, no. 3, pp. 298-317, (2012).

31. A. Jakobsen and L. L. Bucciarelli, "Transdisciplinary variation in engineering curricula. Problems and means for solutions.," Eur. J. Eng. Educ., vol. 32, no. 3, pp. 295-301, (2007). 
32. L. Vanasupa, K. E. McCormick, C. J. Stefanco, R. J. Herter, and M. McDonald, "Challenges in Transdisciplinary, Integrated Projects: Reflections on the Case of Faculty Members' Failure to Collaborate," Innov. High. Educ., vol. 37, no. 3, pp. 171184, (2012).

33. N. Chabrak and R. Craig, "Student imaginings, cognitive dissonance and critical thinking," Crit. Perspect. Account., vol. 24, no. 2, pp. 91-104, (2013).

34. S. S. Chave, "Education, sustainability and intersubjectivity: exploring the possibility of the emergence of new ways of knowing, being and acting in the world." University of Exeter, (2017).

35. J. Davies, J. White, A. Wright, Y. Maru, and M. LaFlamme, “Applying the sustainable livelihoods approach in Australian desert Aboriginal development," Rangel. J., vol. 30, no. 1, pp. 55-65, (2008).

36. J. Altman and J. Finlayson, “Aborigines, tourism and sustainable development," $J$. Tour. Stud., vol. 4, no. 1, pp. 38-50, (1993).

37. G. P. Means, "The Orang Asli: Aboriginal Policies in Malaysia," Pac. Aff., vol. 58, no. 4, pp. 637-652, (1985).

38. P. Vare and W. Scott, "Learning for a Change: Exploring the Relationship Between Education and Sustainable Development opinion essay," vol. 1, no. 2, pp. 191-198, (2015).

39. P. Ekins, "Making development sustainable," Glob. Ecol. A new arena Polit. Confl., pp. 91-103, (1993).

40. P. P. Mollinga, "Towards the transdisciplinary engineer: Incorporating ecology, equity and democracy concerns into water professionals' attitudes, skills and knowledge," Irrig. Drain., vol. 58, no. S2, pp. 195-204, (2009). 